\title{
Experimental Study on Direct Shear Mechanical Characteristics of Warm Frozen Silty Clay
}

\author{
Fengpan Zhu, Lanyun Chen*, Yonghe Yao, Quanwei Zhao, Junhu Li \\ Architectural Engineering Institute, Jinhua Polytechnic, Jinhua 321017, China \\ Corresponding Author Email: zjjhcly@163.com
}

https://doi.org/10.18280/acsm.440107

Received: 15 August 2019

Accepted: 28 November 2019

\section{Keywords:}

warm frozen soil, stress-strain, direct shear, Qinghai-Tibet plateau

\begin{abstract}
The strength of the warm frozen soil is the key to the design of buildings and structures in the permafrost region, laying the basis for the safe operation and stability evaluation in the later stage of building/structure projects. In this paper, the frozen red silty clay is collected from Wudaoliang section of Qinghai-Tibet Highway, and prepared into samples for direct shear experiments. During the experiments, the direct shear properties of the samples were observed under different densities, normal stresses, water contents, temperatures, etc. The results show that, with the growing density, the cohesion of the frozen silty clay continues to increase, while the internal friction angle decreases first and then increases; with the growth in water content, the cohesion and internal friction angle show the same trends, but the angle increment is small; with the increase in normal stress, the internal friction angle exhibits a declining trend; the shear strength of the frozen soil has a linear relationship with temperature. Through theoretical analysis, the author established an expression for the relationship between shear strength and temperature of warm frozen soil at $0 \sim-2^{\circ} \mathrm{C}$, and confirmed that the shear stress-strain relationship of the frozen silty clay belongs to the strain hardening type, which obeys the hyperbolic model proposed by Clough and Duncan. The research findings lay a solid basis for the building/structure design in permafrost regions.
\end{abstract}

\section{INTRODUCTION}

About 25\% of the Earth's land surface is covered by permafrost, i.e. perennially frozen soil. The permafrost regions mainly exist in Russia, China and North America. The majority (70\%) of China's permafrost concentrates in Qinghai and Tibet. The Qinghai-Tibet Railway passes through this permafrost region, including $275 \mathrm{~km}$ through warm frozen soil (annual mean ground temperature $>-1.0^{\circ} \mathrm{C}$ ) and $221 \mathrm{~km}$ in icy frozen soil (ice content $>20 \mathrm{vol} \%$ ) [1]. It is a must to know the mechanical properties of frozen soil before conducting engineering construction in the frozen soil region [2]. Zhu et al. [3] established the parabolic strength criterion for frozen soil through tri-axial tests. Lai et al. [4] conducted tri-axial compressive tests on warm ice-rich frozen silt and mapped the strength distribution of warm ice-rich frozen silt. Qin et al. [5] studied the compressible behavior of frozen soil remolded in the laboratory from the permafrost sample in situ. Zhang et al. [6] performed lateral loading tests and uniaxial compression tests on frozen remolded clay in the lab. These results reveal the uniaxial strength and transient tri-axial strength of frozen soil.

Besides, scholars have also done a lot of research on the shear features of frozen soil under low temperature and high pressure. Arenson et al. [7] investigated the creep and strength features of frozen soil under tri-axial stress. Liao et al. [8] carried out tri-axial creep test on high temperature frozen silt and established a creep model. Qu et al. [9] probed into the direct shear creep features and long-term strength of frozen silty clay at $-2^{\circ} \mathrm{C}$. Huang et al. [10] examined the shear creep features of frozen soil at $-2^{\circ} \mathrm{C}$. Arenson et al. [11] mathematically described the thermomechanical behavior of ice-rich frozen soils through creep and constant strain rate (CSR) tests. Bray et al. [12, 13] performed unconfined constant stress creep (CSC) tests on warm permafrost, and conducted transient relaxation tests to approximate the secondary creep of ice-rich soils and ice. Yang et al. [14] examined the shear creep behavior of warm ice-rich frozen soils. Yao et al. [15] developed a frozen soil creep model with shear strength attenuation. Li et al. [16] explored the shear properties of frozen silty clay under cyclic tri-axial tests. Czurda et al. [17] carried out a direct shear test on five kinds of frozen clay, aiming to disclose the effects of different freezing conditions at the shearing plane on the shear strength of the thawing clayey soils. Weaver et al. [18] performed direct shear tests on frozen soil and ice. Fitzsimons et al. [19] conducted a direct shear test on frozen soil at $-17^{\circ} \mathrm{C}$. Lu et al. [20] described the field shear test in the Huangji $220 \mathrm{kV}$ transmission line, which passes across the permafrost region of the Tianshan Mountains, Xinjiang Uyghur Autonomous Region. However, there are not many reports on the shear mechanical properties of warm permafrost.

In Tibet Autonomous Region, the shear mechanical properties of the warm permafrost must be considered in the construction of infrastructure, including highways, power transmission lines and pipelines. Therefore, this paper remolds the frozen silty clay from Qinghai-Tibet region in the lab, and explores how the shear strength of the clay is affected by normal stress, density, temperature, water content. The research results lay the basis for construction projects on warm permafrost of the Qinghai-Tibet Plateau. 


\section{METHODOLOGY}

\subsection{Sample preparation}

The frozen red silty clay was collected from Wudaoliang section of Qinghai-Tibet Highway. Table 1 shows the liquid and plastic limits of the remolded silty clay.

Table 1. The liquid and plastic limits

\begin{tabular}{cccc}
\hline $\begin{array}{c}\text { Specific } \\
\text { weight }\end{array}$ & $\begin{array}{c}\text { Liquid limit } \\
\mathbf{/ \%}\end{array}$ & $\begin{array}{c}\text { Plastic limit } \\
\mathbf{/ \%}\end{array}$ & $\begin{array}{c}\text { Plasticity } \\
\text { index } \boldsymbol{I}_{\boldsymbol{p}}\end{array}$ \\
\hline 2.70 & 27.0 & 15.6 & 11.4 \\
\hline
\end{tabular}

The frozen silty clay samples were prepared in the following steps:

Step 1. Filter the remolded soil with a $2 \mathrm{~mm}$ sieve, and place the sieved soil in a freezing chamber at $-2^{\circ} \mathrm{C}$. Keep the temperature for $48 \mathrm{~h}$ to fully cool down the soil.

Step 2. Calculate the masses of remolded soil $m_{d}$, water $m_{w}$ and ice $m_{i}$ required to prepare a direct shear sample, according to the designed density and water content of our experiments.

Step 3. Crush the pre-frozen ice sample and filter the fragments with a $5 \mathrm{~mm}$ sieve in the freezing chamber at $-5^{\circ} \mathrm{C}$, creating ice crystals of $-2^{\circ} \mathrm{C}$.

Step 4. Weight $n \cdot m_{d}$ of pre-cooled remolded soil and $n \cdot m_{i}-$ $2{ }^{\circ} \mathrm{C}$ of ice crystals, mix them in a plastic bag and stir well; next, add $n \cdot m_{w}$ of distilled water of around $0^{\circ} \mathrm{C}$ into the mixture, and stir well.

Step 5. Quickly load the soil sample into a pre-cooled mold, compress the sample by three layers, and freeze the compressed sample at $-2^{\circ} \mathrm{C}$.

\subsection{Experimental procedure}

Our experiments were conducted on an EDJ-1 straincontrolled direct shear instrument (Nanjing Soil Instrument, China), at the shear rate of $0.8 \mathrm{~mm} / \mathrm{min}$. The experimental procedure is explained as follows:

Step 1. Prepare the sample in the freezing chamber, relocate the prepared sample into a thermostatic cabinet for $24 \mathrm{~h}$ freezing at $-20^{\circ} \mathrm{C}$

Step 2. Adjust the temperature in the freezing chamber to the designed temperature for our experiments, and maintain that temperature for $24 \mathrm{~h}$.

Step 3. Place the frozen soil sample into the freezing chamber, adopt heat preservation measures, and measure the frozen soil temperature with a thermistor in real time; perform the direct shear experiment once the sample temperature reaches the required temperature.

Step 4. Check the direct shear instrument, and apply Vaseline at the contact between upper and lower shear boxes and within the boxes.

Step 5. Place the sample onto the instrument, apply vertical load and then horizontal shear load, and seal up the sheardamaged sample.

\section{RESULTS ANALYSIS}

\subsection{Density}

The original frozen silty clay usually has a greater water content than the liquid limit. Therefore, the water content was set close to the liquid limit, before analyzing the impact of density on the shear strength of the remolded frozen silty clay. The water content of our samples was set to $30 \%$, close to the liquid limit of the selected silty clay $(27 \%)$.

Figure 1 presents the shear strength curves of frozen silty clays with densities $\rho$ of $1.33 \mathrm{~g} \cdot \mathrm{cm}^{-3}, 1.50 \mathrm{~g} \cdot \mathrm{cm}^{-3}, 1.60 \mathrm{~g} \cdot \mathrm{cm}^{-3}$ and $1.83 \mathrm{~g} \cdot \mathrm{cm}^{-3}$, respectively, with the temperature $\theta=-2.0^{\circ} \mathrm{C}$ and water content $w=30 \%$. Under the normal stress of $200 \mathrm{kPa}$, the frozen silty clay with the density of $\rho=1.33 \mathrm{~g} \cdot \mathrm{cm}^{-3}$ may shrink excessively, due to the small density. For convenience, only three normal stresses were selected.

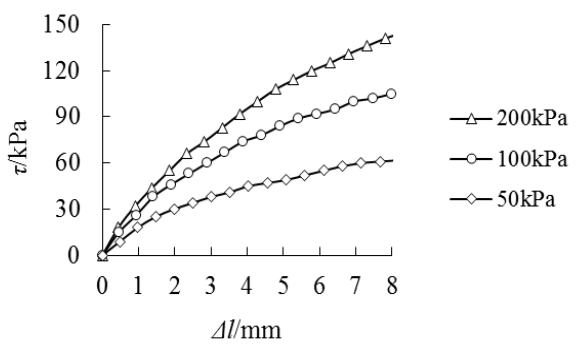

(a) $\rho=1.33 \mathrm{~g} \cdot \mathrm{cm}^{-3}$

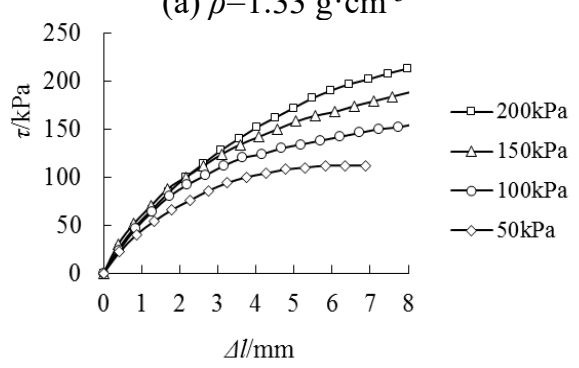

(b) $\rho=1.50 \mathrm{~g} \cdot \mathrm{cm}^{-3}$

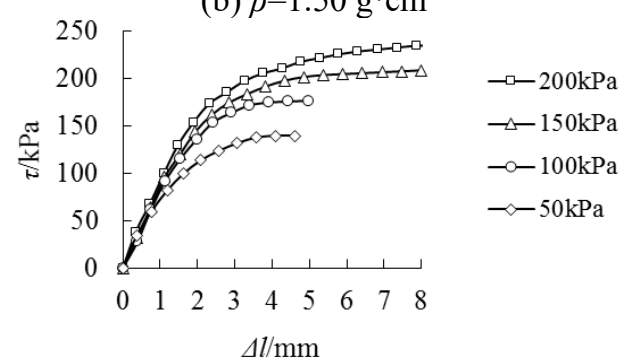

(c) $\rho=1.60 \mathrm{~g} \cdot \mathrm{cm}^{-3}$

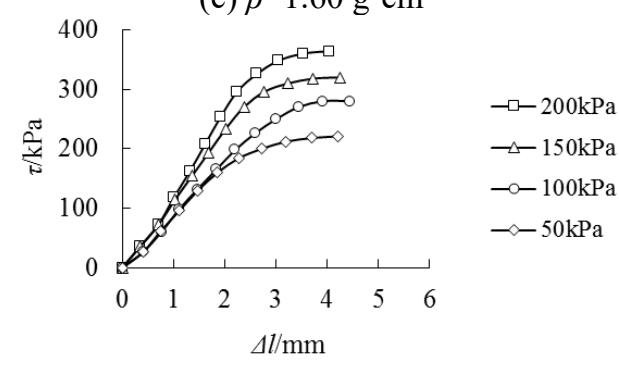

(d) $\rho=1.83 \mathrm{~g} \cdot \mathrm{cm}^{-3}$

Figure 1. Shear strength curves of frozen silty clay samples with different densities

As shown in Figure 1, the shear failure modes of the frozen soil varied with the densities, under the constant water content, temperature, soil properties and shear rate. With the growing density, the displacement-shear strength $(\Delta l \sim \tau)$ curve of each frozen silty clay sample reflects the shift from strain hardening to strain softening, and from plastic failure to brittle failure. Under the density of $1.83 \mathrm{~g} \cdot \mathrm{cm}^{-3}$, the shear displacement was only $4 \mathrm{~mm}$, and failure mode is strain softening. 
As shown in Figure 2, the internal friction angle $\varphi$ of frozen silty clay samples decreased first and then increased, with the growth in sample density. The minimum internal friction angle $\left(30^{\circ}\right)$ appeared at the density of $1.60 \mathrm{~g} \cdot \mathrm{cm}^{-3}$. Meanwhile, the cohesion c always increases with density.

There are two possible reasons for these trends: (1) When the density of frozen soil increases below $1.60 \mathrm{~g} \cdot \mathrm{cm}^{-3}$, the frozen soil faces the rise of void ratio and the decline of saturation. Thus, the soil structure is prone to damage under normal stress. As a result, the cohesion shows a positive correlation with density, while the internal friction angle exhibits a negative correlation with density. (2) When the density of frozen soil grows above $1.60 \mathrm{~g} \cdot \mathrm{cm}^{-3}$, the frozen soil sees the decline of void ratio and the rise of saturation, i.e. the soil particles become closer to each other. Therefore, both internal friction angle and cohesion of the frozen soil increases with the soil density.

Table 2 illustrates how void ratio and saturation change with soil density.

The above analysis shows: the frozen silty clay with a density below $1.60 \mathrm{~g} \cdot \mathrm{cm}^{-3}$ has relatively large void ratio, and tend to fail under the normal stress; on the contrary, the frozen silty clay with a density above $1.60 \mathrm{~g} \cdot \mathrm{cm}^{-3}$ has relatively small void ratio, and tend to be intact under the normal stress. Hence, the density of frozen silty clay samples was set to $1.60 \mathrm{~g} \cdot \mathrm{cm}^{-3}$ for the subsequent analysis.

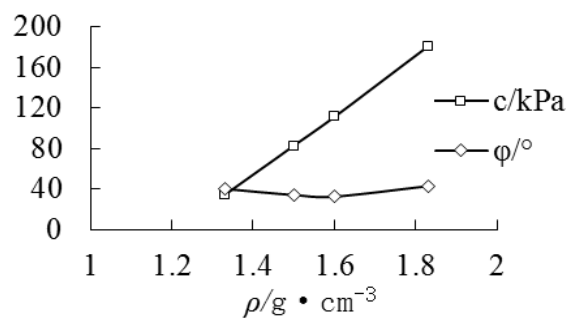

Figure 2. Relationship between shear strength and destiny of frozen silty clay samples

Table 2. Changes of void ratio and saturation with density

\begin{tabular}{ccc}
\hline Density / $\mathbf{g} \cdot \mathbf{c m}^{-\mathbf{3}}$ & Void ratio & Saturation / \% \\
\hline 1.33 & 1.69 & 47.8 \\
1.50 & 1.39 & 58.4 \\
1.60 & 1.23 & 65.4 \\
1.83 & 0.96 & 84.6 \\
\hline
\end{tabular}

\subsection{Normal stress}

According to the Mohr-Coulomb failure criterion, one normal stress corresponds to one shear stress. Therefore, the magnitude and expression of the displacement-shear strength $(\Delta l \sim \tau)$ curve of the frozen soil will vary with the normal stresses, while the other conditions (e.g. soil properties, temperature, density, water content and shear rate) remain the same.

Figure 3 provides the shear strength curves of frozen silty clay samples under seven different normal stresses, at the temperature $\theta=-2.0^{\circ} \mathrm{C}$, density $\rho=1.60 \mathrm{~g} \cdot \mathrm{cm}^{-3}$ and water content $w=30 \%$. It can be seen that the internal friction angle and cohesion of frozen silty clay were $30^{\circ}$ and $114.5 \mathrm{kPa}$ respectively, when the normal stress increased from 50 to $200 \mathrm{kPa}$. When the normal stress increased from 200 to $400 \mathrm{kPa}$, the internal friction angle and cohesion of frozen silty clay were $28^{\circ}$ and $117.9 \mathrm{kPa}$. In other words, the internal friction angle narrowed with the growth in normal stress.

This phenomenon can be attributed to the following factor: When the normal stress is below $200 \mathrm{kPa}$, the frozen silty clay is not greatly compressed; with the increase of the normal stress, the frozen soil undergoes structural damage, and uneven surfaces appear between soil particles; further growth of the normal stress will squeeze the uneven surfaces, making the soil structure more fragmented. In this way, the internal friction angle of the frozen soil will decrease.

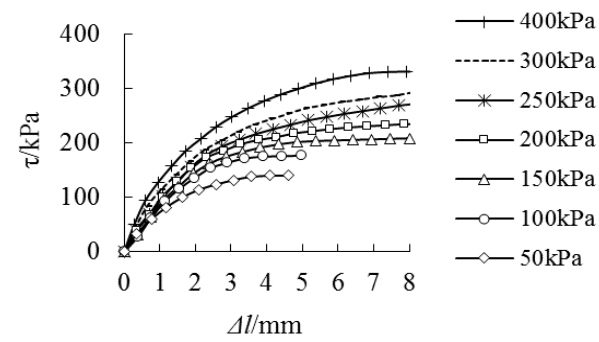

(a) Displacement-shear strength $(\Delta l \sim \tau)$ curves

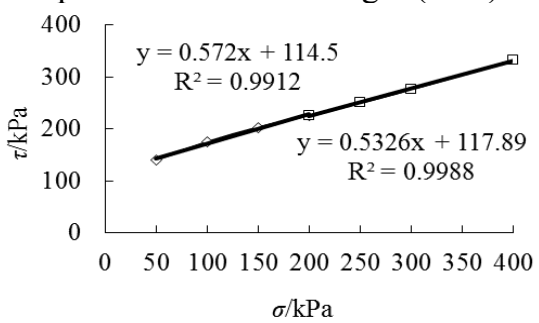

(b) Normal stress-shear strength $(\sigma \sim \tau)$ curves

Figure 3. Shear strength curves of frozen silty clay samples under different normal stresses

\subsection{Water content}

Figure 4 displays the shear strength curves of frozen silty clay samples with different water contents $w: 10 \%, 17 \%$ and $50 \%$. The temperature and density were kept constant at -2.0 ${ }^{\circ} \mathrm{C}$ and $1.60 \mathrm{~g} \cdot \mathrm{cm}^{-3}$, respectively.

As shown in Figure 4, with the rise in water content, each frozen silty clay sample witnessed the shift from strain hardening to strain softening, and from plastic failure to brittle failure. When the water content reached $50 \%$, the shear displacement was merely $6.5 \mathrm{~mm}$.

According to the shear strength curves of pure ice at $-2.0^{\circ} \mathrm{C}$ (Figure 5), the pure ice suffered from brittle failure at the shear displacement of $2.5 \mathrm{~mm}$, with a cohesion of $688 \mathrm{kPa}$ and an internal friction angle of $55.6^{\circ}$. It can be derived that, with further increase in water content, the frozen soil will exhibit properties similar as the pure ice: the shear displacement will decrease, while the shear strength will increase.

As shown in Figure 6, the internal friction angle $\varphi$ of frozen silty clay decreased first and then increased, with the growth in water content. The increment was very small: the angle widened by $2^{\circ}$, as the water content rose from $30 \%$ to $50 \%$. Moreover, the internal friction angle was minimized, when the water content reached the liquid limit. By contrast, the cohesion $c$ showed a linear increase with the growing water content.

The main reasons for the above results include: (1) When the water content grows below the liquid limit, the saturation of the frozen soil decreases, and the cementation between soil particles and ice weakens, inducing a decline in soil cohesion; 
when the water content decreases below the liquid limit, the void ratio of the frozen soil falls (Table 3), the soil particles become heavier and more closely bonded, and the internal friction angle will increase. (2) When the water content increases above the liquid limit, the saturation of the frozen soil increases, and the soil strength depends heavily on ice. The higher the water content, the greater the internal friction angle and cohesion. Once the water content reaches the liquid limit, the internal friction angle and cohesion will arrive at very high levels.

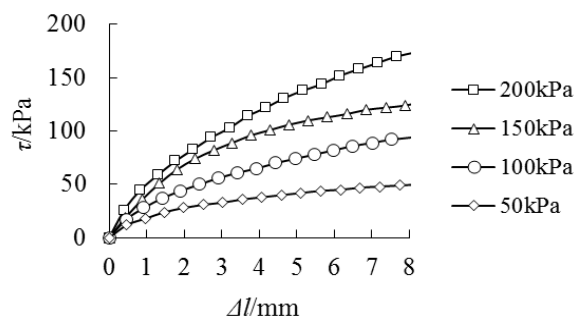

(a) $w=10 \%$

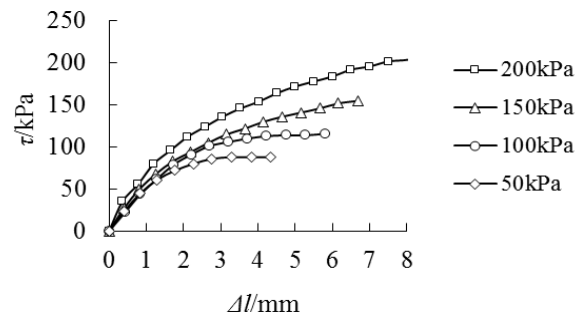

(b) $w=17 \%$

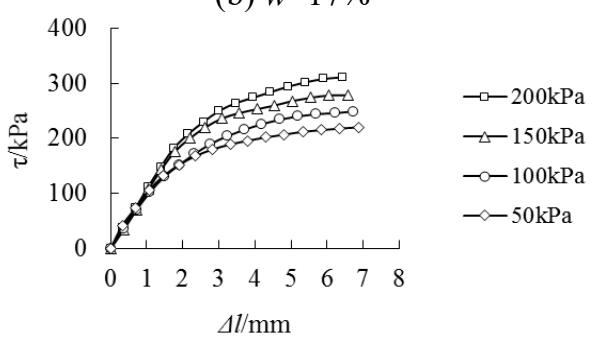

(c) $w=50 \%$

Figure 4. Shear strength curves of frozen silty clay samples with different water contents

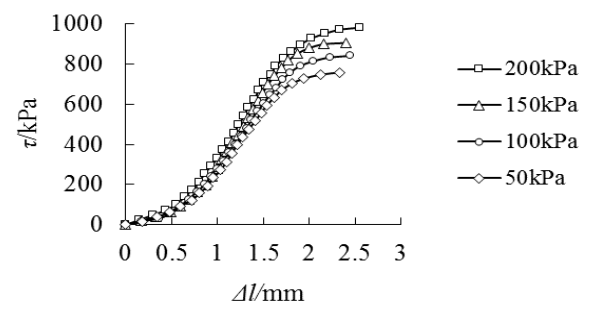

(a) Displacement-shear strength $(\Delta l \sim \tau)$ curves

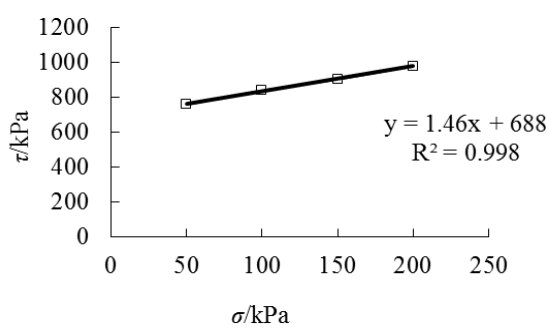

(b) Normal stress-shear strength $(\sigma \sim \tau)$ curves

Figure 5. Shear strength curves of pure ice

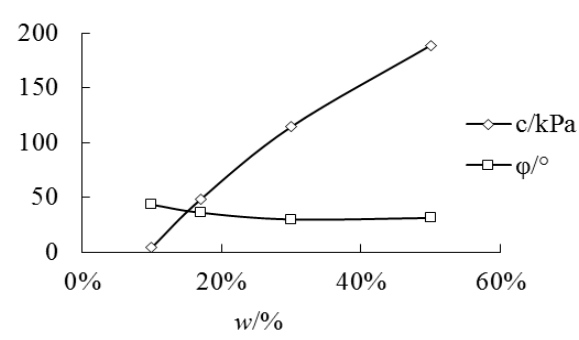

Figure 6. Relationship between shear strength and water content

Table 3. Changes of void ratio and saturation with water contents

\begin{tabular}{ccc}
\hline Water content / \% & Void ratio & Saturation / \% \\
\hline 10 & 0.89 & 30.2 \\
17 & 1.01 & 45.2 \\
30 & 1.23 & 65.4 \\
50 & 1.58 & 85.3 \\
Pure ice & $+\infty$ & 100 \\
\hline
\end{tabular}

\subsection{Temperature}

Temperature is the key factor that differentiates frozen soil from unfrozen soil. When the temperature drops to or below zero, the water in the soil will become ice. Close to the freezing point, the temperature $-2^{\circ} \mathrm{C}$ has a great impact on the mechanical properties of the frozen soil. Hence, the effect of direct shear experiments hinges on temperature control. Figure 7 shows the shear strength curves of frozen silty clay samples at different temperatures: $-0.2^{\circ} \mathrm{C},-1.0^{\circ} \mathrm{C}$ and $-1.7^{\circ} \mathrm{C}$. The density and water content of the samples were controlled constant at $\rho=1.60 \mathrm{~g} \cdot \mathrm{cm}^{-3}$ and $w=30 \%$, respectively. Figure 8 reflects the variation of shear strength with temperatures.

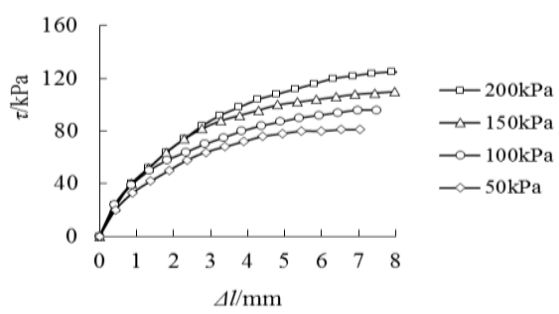

(a) $\theta=-0.2^{\circ} \mathrm{C}$

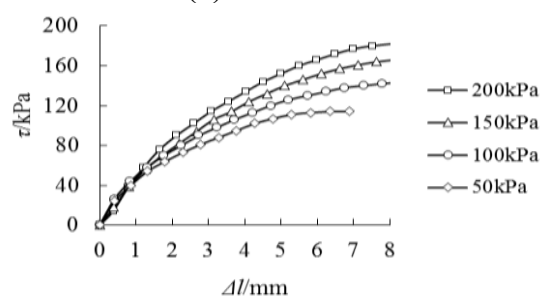

(b) $\theta=-1.0^{\circ} \mathrm{C}$

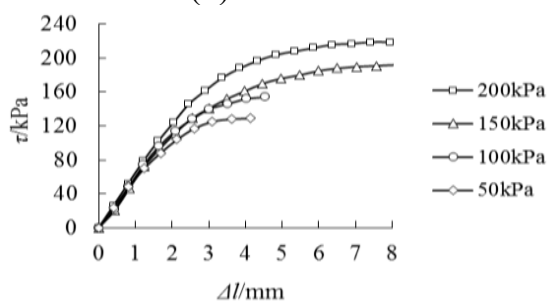

(c) $\theta=-1.7^{\circ} \mathrm{C}$

Figure 7. Shear strength curves of frozen silty clay samples at different temperatures 
Table 4 records the changes of cohesion and internal friction angle with temperatures. From these figures and table, it is learned that, with the decline of temperature, the displacement-shear strength $(\Delta l \sim \tau)$ curve of each frozen silty clay sample demonstrates the trend from strain hardening to strain softening, while density, water content, soil properties and shear rate remained the same. With the decrease in temperature, both cohesion and internal friction angle were on the rise.

Table 4. Changes of cohesion and internal friction angle with temperatures

\begin{tabular}{ccc}
\hline $\begin{array}{c}\text { Temperature } \\
{ }^{\circ} \mathbf{C}\end{array}$ & $\begin{array}{c}\text { Internal friction angle } \\
\boldsymbol{\rho} /{ }^{\circ}\end{array}$ & $\begin{array}{c}\text { Cohesion } \\
\boldsymbol{c ~} \mathbf{k P a}\end{array}$ \\
\hline-0.2 & 16.6 & 65.5 \\
-1 & 24.9 & 93 \\
-1.7 & 28.8 & 105 \\
-2.0 & 29.8 & 114.5 \\
\hline
\end{tabular}

As shown in Figure 8, the shear strength of each frozen soil sample changed linearly with temperature. Hence, the relationship between shear strength and temperature of frozen silty clay at $\rho=1.60 \mathrm{~g} \cdot \mathrm{cm}^{-3}, w=30 \%, \nu=0.8 \mathrm{~mm} \cdot \mathrm{min}^{-1}$ and $\theta=0 \sim-2^{\circ} \mathrm{C}$ can be expressed as:

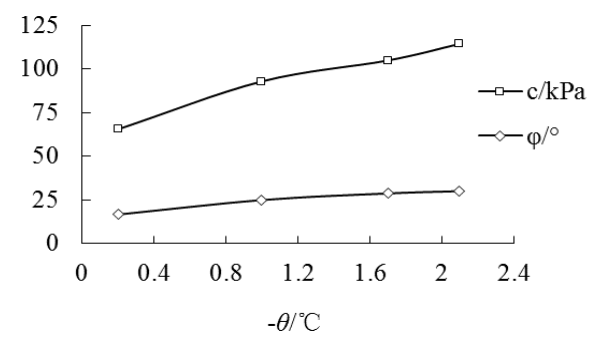

Figure 8. Relationship between shear strength and temperature

$$
\begin{gathered}
\varphi=7.06|\theta|+16 \\
c=25.14|\theta|+63 \\
\tau=\sigma \tan (7.06|\theta|+16)+25.14|\theta|+63
\end{gathered}
$$

\subsection{Shear stress-strain relationship}

Through analysis, it is learned that the shear stress-strain relationship of remolded frozen soil could be hardening or softening, depending on temperature, density, normal stress, water content and shear rate. Figure 9 presents the displacement-shear strength $(\Delta l \sim \tau)$ curves of frozen silty clay samples at the temperature, density and water content of $\theta=-$ $2.0^{\circ} \mathrm{C}, \rho=1.50 \mathrm{~g} \cdot \mathrm{cm}^{-3}$ and $w=30 \%$, respectively. The $\Delta l \sim \tau$ curves in that figure are typical curves for strain hardening.

For the strain-hardening type frozen silty clay, the relationship between shear stress $\tau$ and shear strain $\varepsilon$ can be fitted by the hyperbolic model proposed by Clough and Duncan:

$$
\frac{\varepsilon}{\tau}=a+b \varepsilon
$$

Table 5 sums up the frozen silty clay parameters fitted by the hyperbolic model. The results confirm that the shear stressstrain relationship of frozen silty clay with strain hardening can be fitted well by that model.

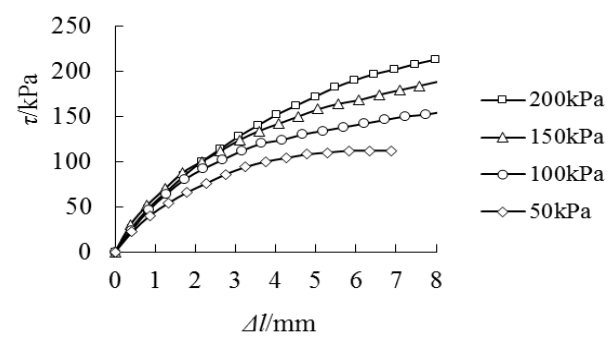

Figure 9. Shear strength curves of frozen silty clay samples

Table 5. Parameters of frozen silty clay samples fitted by hyperbolic model

\begin{tabular}{cccc}
\hline Normal stress $/ \mathbf{k P a}$ & $\mathbf{a}$ & $\mathbf{b}$ & $\boldsymbol{R}^{2}$ \\
\hline 50 & 0.0063 & 0.0002 & 0.9914 \\
100 & 0.0048 & 0.0002 & 0.9992 \\
150 & 0.0037 & 0.0002 & 0.9981 \\
200 & 0.0030 & 0.0002 & 0.9955 \\
\hline
\end{tabular}

\section{CONCLUSIONS}

This paper mainly explores the direct shear properties of remolded frozen silty clay from Qinghai-Tibet Plateau, focusing on the influence of different factors on the shear strength. The main conclusions are as follows:

(1) With the growth in normal stress, the frozen soil is prone to structural damages under a large normal stress. On the one hand, the structural damages will create uneven surfaces between soil particles, increasing the internal friction angle of the frozen soil; on the other hand, further growth in the normal stress will intensity the damages on the uneven surface between soil particles, reducing the internal friction angle.

(2) Under the temperature of $-2.0^{\circ} \mathrm{C}$ and a normal stress below $200 \mathrm{kPa}$, the cohesion $c$ of the frozen silty clay with density of $1.60 \mathrm{~g} \cdot \mathrm{cm}^{-3}$ will increase with its water content, mainly because the bonding strength of the ice is positively correlated with water content. Meanwhile, the internal friction angle $\varphi$ decreases first and then increases, with the rise in density. This is mainly due to the small void ratio at a low water content. In this case, the soil particles take up much of the frozen soil, resulting in a large internal friction angle.

(3) The shear strength of the frozen silty clay has a linear relationship with temperature. Under the density $\rho=1.60 \mathrm{~g} \cdot \mathrm{cm}^{-}$ 3 , water content $w=30 \%$, shear rate $v=0.8 \mathrm{~mm} \cdot \mathrm{min}^{-1}$ and temperature $\theta=0 \sim-2^{\circ} \mathrm{C}$, the relationship can be expressed as:

$$
\begin{gathered}
\varphi=7.06|\theta|+16 \\
c=25.14|\theta|+63 \\
\tau=\sigma \tan (7.06|\theta|+16)+25.14|\theta|+63
\end{gathered}
$$

(4) The shear stress-strain curve of the frozen silty clay reflects strain hardening, and can be fitted by the hyperbolic model $\frac{\varepsilon}{\tau}=a+b \varepsilon$. 


\section{ACKNOWLEDGMENT}

This work was supported by Jinhua Science and Technology Research Program (Grant No.: 2019-4-167).

\section{REFERENCES}

[1] Ma, X.J., Zhang, J.M., Chang, X.X., Zhang, B., Zhang, M.Y. (2007). Experimental study on creep of warm and ice-rich frozen soil. Chinese Journal of Geotechnical Engineering, 29(6): 849-852.

[2] Qi, J., Ma, W. (2010). State-of-art of research on mechanical properties of frozen soils. Rock and Soil Mechanics, 31(1):

$133-143$ https://doi.org/10.16285/j.rsm.2010.01.036

[3] Zhu, Z., Ning, J., Ma, W. (2006). Study on yield surface and yield criterion of frozen soil. Chinese Journal of Solid Mechanics, 27(3): 308-310. https://doi.org/10.19636/j.cnki.cjsm421250/o3.2006.03.016

[4] Lai, Y.M., Li, J.B., Li, Q.Z. (2012). Study on damage statistical constitutive model and stochastic simulation for warm ice-rich frozen silt. Cold Regions Science and Technology, 71: $102-110$ https://doi.org/10.1016/j.coldregions.2011.11.001

[5] Qin, Y.H., Zhang, J.M, Zheng, B., Ma, X.J. (2009). Experimental study for the compressible behavior of warm and ice-rich frozen soil under the embankment of Qinghai-Tibet Railroad. Cold Regions Science and Technology, 57(2-3): 148-153. https://doi.org/10.1016/j.coldregions.2009.02.006

[6] Zhang, H., Zhang, J.M., Su, K., Liu, S.W. (2015). Comparison between pressuremeter test and uniaxial compression test of frozen soil. Journal of Jilin University (Earth Science Edition), 45(5): 1479-1484. https://doi.org/10.13278/j.cnki.jjuese.201505202

[7] Arenson, L.U., Springman, S.M. (2005). Triaxial constant stress and constant strain rate tests on ice-rich permafrost samples. Canadian Geotechnical Journal, 42(2): 412-430. https://doi.org/10.1139/t04-111

[8] Liao, M.K., Lai, Y.M., Liu, E.L., Wan, X.S. (2016). A fractional order creep constitutive model of warm frozen silt. Acta Geotechnica, 12(2): 377-389. https://doi.org/10.1007/s11440-016-0466-4

[9] Qu, G.Z., Zhang, J.M., Cheng, D.X. (2011). Rock and Soil Mechanics. Experimental study of direct shear creep properties of frozen silty clay on Qinghai-Tibetan Plateau. Rock and Soil Mechanics, 32(1): 95-98. https://doi.org/10.16285/j.rsm.2011.01.051

[10] Huang, Y.S., Li, P., Yan, F.Z., Wang, Y.B., Cheng, D.X.
(2014). Analysis and prediction on long-term shear strength of frozen soil and its influence factors along Qing-Tibet dc transmission line. Journal of Engineering Geology 22(3): 507-514. https://doi.org/10.13544/j.cnki.jeg.2014.03.021

[11] Arenson, L.U., Springman, S.M. (2005). Mathematical descriptions for the behaviour of ice-rich frozen soils at temperatures close to $0^{\circ} \mathrm{C}$. Canadian Geotechnical Journal, 42(2): 431-442. https://doi.org/10.1139/t04-109

[12] Bray, M.T. (2012). The influence of cryostructure on the creep behavior of ice-rich permafrost. Cold Regions Science and Technology, 79-80(8): 43-52. https://doi.org/10.1016/j.coldregions.2012.04.003

[13] Bray, M.T. (2013). Secondary creep approximations of ice-rich soils and ice using transient relaxation tests. Cold Regions Science and Technology, 88(3):17-36. https://doi.org/10.1016/j.coldregions. 2012.12.011

[14] Yang, Y.G., Lai, Y.M., Chang, X.X. (2010). Experimental and theoretical studies on the creep behavior of warm ice-rich frozen sand. Cold Regions Science Technology, 63(1-2): 61-67. https://doi.org/10.1016/j.coldregions.2010.04.011.

[15] Yao, X.L., Qi, J.L., Liu, M.X., Fan, Y. (2017). A frozen soil creep model with strength attenuation. Acta Geotechnica, 12: 1385-1393. https://doi.org/10.1007/s11440-017-0554-0

[16] Li, Q.L., Ling, X.Z., Hu, J.J., Xu, X.T. (2018). Experimental investigation on dilatancy behavior of frozen silty clay subjected to long-term cyclic loading. Cold Regions Science Technology, 153: 156-163. https://doi.org/10.1016/j.coldregions.2018.05.008

[17] Czurda, K.A., Hohmann, M. (1997). Freezing effect on shear strength of clayey soils. Applied Clay Science, 12(1-2): 165-187. https://doi.org/10.1016/S01691317(97)00005-7

[18] Weaver, J.S., Morgenstern, N.R. (1981). Simple shear creep tests on frozen soils. Canadian Geotechnical Journal, 18(2): 217-229. https://doi.org/10.1139/t81-026

[19] Fitzsimons, S.J., McManus, K.J., Sirota, P., Lorrain, R.D. (2001). Direct shear tests of materials from a cold glacier: implications for landform development. Implications for Landform Development, Quaternary International, 86(1): 129-137. https://doi.org/10.1016/S1040-6182(01)000556

[20] Lu, X.L., Cheng, Y.F., Fei, X.Z., Man, G.M., Guo, Y.S. $\mathrm{Xu}, \mathrm{B}$. (2004). Field tests on mechanical chariceristics of permafrost along Tianshan section of Huangji $220 \mathrm{kV}$ transmission line. Chinese Journal of Rock Mechanics and Engineering, 23(z1): 4383-4387. https://doi.org/10.3321/j.issn:1000-6915.2004.z1.023 